\title{
Characterization of Bacillus Species from Market Foods in Beijing, China
}

\author{
Qiao Hu ${ }^{1,2,+}$, Yuwen Fang ${ }^{1,2,+}$, Jiajia Zhu ${ }^{1,2}$, Wenjiao Xu ${ }^{1,2}$ and Kui Zhu 1,2,* \\ 1 College of Veterinary Medicine, China Agricultural University, Beijing 100193, China; \\ huqiao@cau.edu.cn (Q.H.); fangyuwen@cau.edu.cn (Y.F.); zhujiajia@cau.edu.cn (J.Z.); xwjvet@163.com (W.X.) \\ 2 National Center for Veterinary Drug Safety Evaluation, College of Veterinary Medicine, \\ China Agricultural University, Beijing 100193, China \\ * Correspondence: zhuk@cau.edu.cn \\ + These authors contributed equally to this article.
}

check for

updates

Citation: Hu, Q.; Fang, Y.; Zhu, J.; $\mathrm{Xu}, \mathrm{W}$; Zhu, K. Characterization of Bacillus Species from Market Foods in Beijing, China. Processes 2021, 9, 866 https://doi.org/10.3390/pr9050866

Academic Editor: Nevijo Zdolec

Received: 15 April 2021

Accepted: 11 May 2021

Published: 14 May 2021

Publisher's Note: MDPI stays neutral with regard to jurisdictional claims in published maps and institutional affiliations.

Copyright: (C) 2021 by the authors. Licensee MDPI, Basel, Switzerland. This article is an open access article distributed under the terms and conditions of the Creative Commons Attribution (CC BY) license (https:// creativecommons.org/licenses/by/ $4.0 /)$.

\begin{abstract}
Foodborne diseases have been witnessing a constant rising trend worldwide, mainly caused by pathogenic microorganisms, such as Bacillus spp., posing a direct threat to public health. The purpose of this study was to evaluate the biological risk of foodborne and probiotic Bacillus spp. in Beijing markets. A total of 55 Bacillus isolates, including 29 B. cereus, 9 B. licheniformis and 7 B. subtilis, mostly found in dairy products (32.7\%), were recovered from 106 samples and identified by matrix-assisted laser desorption/ionization mass spectrometry and polymerase chain reaction methods. The susceptibility towards 16 antibiotics was determined using a broth microdilution method. Bacillus showed a high level of resistance to florfenicol $(100 \%)$, lincomycin (100\%), tiamulin (78.2\%) and ampicillin (67.3\%), while they were all susceptible or intermediate to vancomycin and rifampin. Additionally, we obtained the whole genome of 19 Bacillus strains using high-throughput sequencing, and the rates of resistance genes van, fosB, erm and tet were $57.9 \%, 57.9 \%, 21.1 \%$ and $26.3 \%$, respectively. Moreover, $100 \%, 9.1 \%, 45.5 \%$ and $100 \%$ of these isolates carried virulence genes nhe, $h b l$, cytK and entFM, respectively. Lastly, $60 \%$ Bacillus strains were positive in hemolysis tests, and 3 B. licheniformis strains displayed an inhibitory activity on the growth of S. aureus ATCC 29213 using agar overlay technique. Our study outlines the characteristics of foodborne Bacillus spp. and provides information for the monitoring of food safety.
\end{abstract}

Keywords: emerging foodborne pathogens; Bacillus; probiotics; antimicrobial resistance

\section{Introduction}

Foodborne diseases are now a widespread and growing problem to public health and the world economy [1-3]. It is estimated that about 600 million people are suffering from foodborne illnesses, such as malaise, diarrhea, etc., which even stimulates the possibility of cancer, leading to 420,000 deaths annually [4,5]. Food safety hazards are associated with the ingestion of poisonous toxins, chemicals, and mostly, bacteria, viruses, or parasites $[6,7]$. Notably, pathogens with the competence of producing toxins play a crucial role in foodborne illnesses [8].

Bacillus species are Gram-positive, spore-forming, rod-shaped, aerobic or facultative anaerobic bacteria, and they are ubiquitously distributed in soil, water, the environment as well as various food products $[9,10]$. By virtue of their multilayer-structured endospores, Bacillus spp. offer high tolerance towards acid, dehydration, $\gamma$-ray and ultraviolet radiation; they are stable during heat processing and low-temperature storage [11-14]. Several Bacillus strains have been screened for their potential probiotic functionalities in animal husbandry, bionematicides and antibiotic alternatives [15,16]. Additionally, they have also been verified to possess pathogen exclusion, anti-oxidant, immuno-modulatory and food fermentation abilities [17-20]. Bacillus and Paenibacillus spp. can yield potent antimicrobial lipopeptides, including polymyxins, octapeptins, polypeptins, iturins, surfactins, fengycins, 
tridecaptins and kurstakins, which are usually secondary metabolites produced by nonribosomal peptide synthetases (NRPSs) [21]. A mixture of D- and L-amino acids equips those lipopeptides with an enhanced ability to withstand proteolytic enzymes from target organisms, as well as human plasma proteases, and potentially enables treatment by oral administration and intravenous injection [21-23].

Nevertheless, Bacillus is an opportunistic pathogen that may cause severe local or systemic infections, such as endophthalmitis and septicemia, when allowed access to mammalian tissues [16]. Few members of Bacillus spp., particularly B. cereus and B. anthracis, are infamous for producing emetic toxins (Cereulide) or enterotoxin. PA-LF (protective antigen- lethal factor) and PA-EF (edema factor) are B. anthracis generated toxins that induce the deadly disease anthrax in humans and animals [24,25]. Cereulide, produced by B. cereus and B. weihenstephanensis, is a major cause of foodborne intoxications through inhibiting the synthesis of RNA, causing expansion of mitochondria and formation of vacuoles in the protoplasm of target cells, thus bringing cell apoptosis and even fulminant liver failure $[26,27]$. Three enterotoxins of $B$. cereus that belong to the family of poreforming toxins (PFTs), including non-hemolytic enterotoxin (Nhe), hemolysin BL ( $\mathrm{Hbl}$ ) and cytolysin K (CytK), are mainly responsible for diarrhea [28-30]. On the other hand, the presence of transferrable antimicrobial resistance genes (ARGs) will endow foods and probiotics containing Bacillus spp. as a reservoir for the transmission of antibiotic resistance [31,32]. Foodborne Bacillus spp. could serve as a vehicle to spread ARGs, while probiotic Bacillus spp. that are excreted through improperly treated animal waste would facilitate the horizontal gene transfer of mobile ARGs. Further, the emergence of antibiotic resistant strains, especially those resistant to multiple antibiotics, can cause routine treatments of $B$. cereus infection to fail $[9,33,34]$. Therefore, the mobile ARGs in Bacillus strains is another safety parameter that requires prompt attention.

The Centers for Disease Control and Prevention (CDC) website claimed that there were 619 confirmed Bacillus-related outbreaks from 1998 to 2015. B. cereus is also the second most frequently found causative agent of confirmed and suspected foodborne outbreaks (FBOs) in France after Staphylococcus aureus [35]. The European Union summary report on trends and sources of zoonoses, zoonotic agents and food-borne outbreaks reported a total of 287 outbreaks caused by B. cereus toxins involving 3073 cases (about $8 \%$ hospitalization) in European Member States (MSs) in 2014, whereas 291 outbreaks involving 3131 cases (with $3 \%$ hospitalization) were reported by nine MSs in 2015 [36]. It is elucidated that rice, pasta, pastry and noodles are associated with emesis, whereas vegetables, meat products and milk products are connected with diarrhea, based on previous epidemiological data [12,37]. Dairy products such as infant formula in the Chinese market have caused a considerable number of B. cereus-induced FBOs [38]. Furthermore, the diarrheal-type disease has been reported more frequently in Northern Europe, such as in Finland and Norway, as well as the emetic-type disease in Japan and the UK, constituting a great challenge both in developed and developing societies $[39,40]$. Our study aims to investigate the potential virulence, molecular characteristics and antibiotic resistance profiles of Bacillus spp. isolated from market foods in Beijing, China, providing information about the prevalence and pathogenicity of Bacillus spp. to further ensure food safety.

\section{Materials and Methods}

\subsection{Sample Collection}

From September to December in 2020, we collected a total of 106 samples, including 31 Beijing specialty food, 29 dairy products, 15 rice products, 11 probiotics, 9 fermented food, 7 raw or cooked meat, 2 soybean milk and 2 snacks from different local markets and restaurants in Beijing, China. All samples were independently kept in sealed, sterile plastic bags, transported directly to the laboratory within $24 \mathrm{~h}$ and stored at $4{ }^{\circ} \mathrm{C}$ or $-20^{\circ} \mathrm{C}$. 


\subsection{Bacterial Isolation and Identification}

Liquid samples were serial-decimally diluted as needed, and solid samples were suspended in phosphate-buffered saline (PBS, $\mathrm{pH}=7.2$ ) as initial dilution before being plated onto the surface of Brilliance Bacillus cereus Agar (Oxoid) and incubated at $37^{\circ} \mathrm{C}$ for $24 \mathrm{~h}$. Blue/green colonies were considered as presumptive B. cereus. The colonies were then transferred into $1 \mathrm{~mL}$ brain heart infusion (BHI, Land Bridge Technology) broth and incubated at $37^{\circ} \mathrm{C}$ for $24 \mathrm{~h}(200 \mathrm{rpm})$. The bacterial cultures were spread on BHI agar, incubated at $37^{\circ} \mathrm{C}$ for another $24 \mathrm{~h}$, and single colonies were chosen for further study.

The species-specific identification was performed by (1) matrix-assisted laser desorption ionization-time of flight mass spectrometry (AXIMA Performance, Shimadzu, Japan). First, bacterial samples were grown on BHA agar plates, and a single colony was selected and smeared directly as a thin film on the steel sample plate; $0.8 \mu \mathrm{L}$ of $70 \%$ formic acid and $1 \mu \mathrm{L}$ of CCA matrix solution (prepared with $50 \%$ acetonitrile and $2.5 \%$ trifluoroacetic acid in pure water) were then dropped onto the smear successively. The loaded sample plate was left for several minutes at room temperature to dry before inserting it into the AXIMA for data acquisition. (2) 16S rRNA sequencing: From cultures grown overnight in BHI at $37^{\circ} \mathrm{C}$, DNA of each isolate was extracted by centrifuging at $5000 \times g$ for $5 \mathrm{~min}$ and resuspending in $50 \mu \mathrm{L}$ Tris-EDTA (TE, Amresco) buffer. The suspensions were boiled in water bath at $100{ }^{\circ} \mathrm{C}$ for $10 \mathrm{~min}$. Then. the tubes were placed on ice immediately for $10 \mathrm{~min}$. The procedure was repeated twice, and samples were centrifuged at $14,000 \times g$ for $5 \mathrm{~min}$ to obtain the genomic DNA of each isolate. All the extracted DNA was stored at $-20^{\circ} \mathrm{C} ; 16 \mathrm{~S}$ rRNA sequence analysis was used to further characterize the Bacillus-like strains, using primers $27 \mathrm{~F}$ and 1492R [41]. PCR products were sent to Tsingke Biological Technology (Beijing, China) for sequencing. Genomic sequences were identified in NCBI nucleotides databases using BLAST program (https:/ / blast.ncbi.nlm.nih.gov/Blast.cgi). The strains with high similarity to $16 \mathrm{~S}$ rRNA sequence of the reference strain (Evalue $=0$ and Max identity $\geq 98 \%$ ) were regarded as Bacillus spp. strains.

\subsection{Antimicrobial Susceptibility Tests}

The minimum inhibitory concentrations (MICs) of isolated Bacillus spp. towards 16 kinds of antimicrobial agents (ampicillin, ceftriaxone, gentamicin, streptomycin, kanamycin, erythromycin, tetracycline, florfenicol, ciprofloxacin, vancomycin, rifampicin, linezolid, lincomycin, tiamulin, chloramphenicol, amoxicillin + clavulanate) were tested using a standard broth microdilution method (Clinical and Laboratory Standards Institutes [CLSI] Supplement M100). Staphylococcus aureus ATCC 29213 was used as the quality control strain.

\subsection{Genome Sequencing and Bioinformatics Analysis}

Bacterial genomes of 19 Bacillus isolates were extracted using a bacterial genome DNA extraction kit (Tiangen Biotech, Beijing, China) and sequenced using the Illumina HiSeq $\times 10$ system (Annoroad, Beijing, China). The draft assemblies of the sequences were obtained with SPAdes 3.0, and antimicrobial resistance genes and virulence genes were screened using Center for Genomic Epidemiology (CGE).

\subsection{Hemolysis Test and Detection of Bacterially Produced Inhibitory Compounds}

(a). The Bacillus strains were cultured on sheep blood agar plate (5\%) to identify the hemolytic properties after incubation at $37^{\circ} \mathrm{C}$ for $24 \mathrm{~h}$.

(b). A single colony of Bacillus was inoculated into $1 \mathrm{~mL}$ of BHI broth. Incubation took place over night with shaking ( $200 \mathrm{rpm}$ ) at $37^{\circ} \mathrm{C} ; 5 \mu \mathrm{L}$ of bacterial suspension was pipetted on the BHA plate, and it was dried in sterile air and incubated at $37^{\circ} \mathrm{C}$ for $24 \mathrm{~h}$. The upper MHA agar layer was seeded with E. coli ATCC 25922/S. aureus ATCC 29213, and it was incubated at $37^{\circ} \mathrm{C}$ for $24 \mathrm{~h}$ after solidification. The production of antimicrobial agents was indicated by the inhibition zone. 


\section{Results}

\subsection{Sample Collection and Bacterial Composition}

A total of 55 Bacillus isolates were obtained from 41 samples (38.7\%), including 29 B. cereus strains, 9 B. licheniformis strains, 7 B. subtilis strains, 5 B. pumilus strains, 2 B. amyloliquefaciens strains, 1 B. taeanensis, 1 B. velezensis and 1 Paenibacillus cookii strain (Figure 1, Figure 2). Moreover, 18 isolates were recovered from dairy products, and 11 isolates were from local specialty foods (Table 1). We found that the dominant species was B. cereus in dairy products, rice products and Beijing specialty foods, while the proportion varied slightly from different sources. The major bacteria in fermented foods and probiotics were B. pumilus and B. licheniformis, respectively. Only 1 B. subtilis strain was isolated from a ham. No B. cereus strain was found in probiotic products (Figure 3). Detailed information about the food source of each strain is listed in Table S1 (Supplementary Material). Taken together, it is clarified that Bacillus spp. was a probable contaminant in market foods, and the main threat could be ascribed to B. cereus.

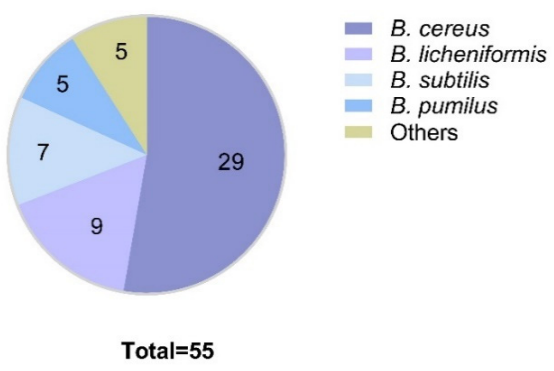

Figure 1. Proportion of different species of Bacillus isolates. B. cereus, B. licheniformis, B. subtilis and B. pumilus constitute $52.7 \%, 16.4 \%, 12.7 \%$ and $9.1 \%$ of the total number, respectively. Other species include B. amyloliquefaciens (3.6\%), B. taeanensis (1.8\%), B. velezensis (1.8\%) and Paenibacillus cookie (1.8\%).

Table 1. Number of samples and bacterial isolates of different sources.

\begin{tabular}{ccc}
\hline Sample Source & No. of Samples & No. of Isolates \\
\hline Beijing specialty food & 31 & 11 \\
Dairy products & 29 & 18 \\
Rice products & 15 & 8 \\
Probiotics & 11 & 9 \\
Fermented food & 9 & 8 \\
Raw or cooked meat & 7 & 1 \\
Soybean milk & 2 & 0 \\
Snacks & 2 & 0 \\
Total & 106 & 55 \\
\hline
\end{tabular}

$\overline{\text { Dairy products include pasteurized milk, yogurt and cheese; rice products include foods made from flour, rice, }}$ noodles and cakes; fermented foods include pickles, kimchi and preserved beancurd.

\subsection{Antimicrobial Susceptibility of Bacillus Isolates}

We subjected all the 55 isolates to antimicrobial susceptibility tests. Generally, Bacillus isolates showed complete resistance to florfenicol and lincomycin. The resistance rates towards ampicillin, amoxicillin + clavulanate and ceftriaxone were $67.3 \%, 54.5 \%$ and $70.9 \%$, respectively (Figure 4). A large proportion of isolates exhibited resistance to streptomycin and tiamulin with levels of $56.4 \%$ and $78.2 \%$. None of the isolates showed tolerance to either rifampin or vancomycin. It is noteworthy that all 29 B. cereus strains were resistant to ampicillin and ceftriaxone, while other Bacillus spp. were mostly sensitive to these two antibiotics (Table 2). B. pumilus isolates were susceptible to 12 antibiotics except for ceftriaxone, florfenicol, lincomycin and tiamulin. Compared with other Bacillus species, $B$. cereus showed more severe resistance to antibacterial agents. In terms of different food sources, Bacillus isolated from dairy products and rice products are highly resistant to penicillin-ampicillin and amoxicillin + clavulanate, for which isolates from vegetables, 
meat and probiotics displayed more sensitivity. Bacillus from probiotics expressed very low resistance to ampicillin, streptomycin, kanamycin, erythromycin, florfenicol, linezolid and lincomycin. Collectively, the presence of resistant strains revealed that antimicrobial resistance may have widely disseminated through Bacillus spp. in the food chain.

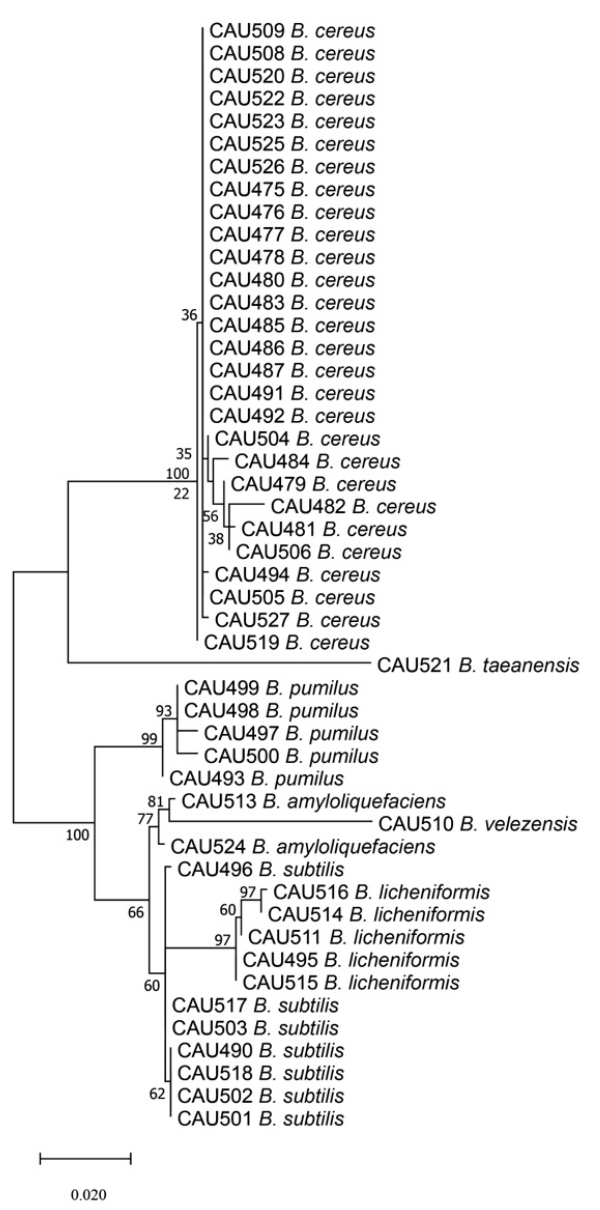

Figure 2. Phylogenetic tree of Bacillus isolates based on $16 \mathrm{~S}$ rRNA sequences. The tree was constructed using maximum likelihood method, and genetic distances were generated using Kimura 2parameter model. The numbers at the branches are bootstrap confidence percentages from 1000 bootstrapped trees.

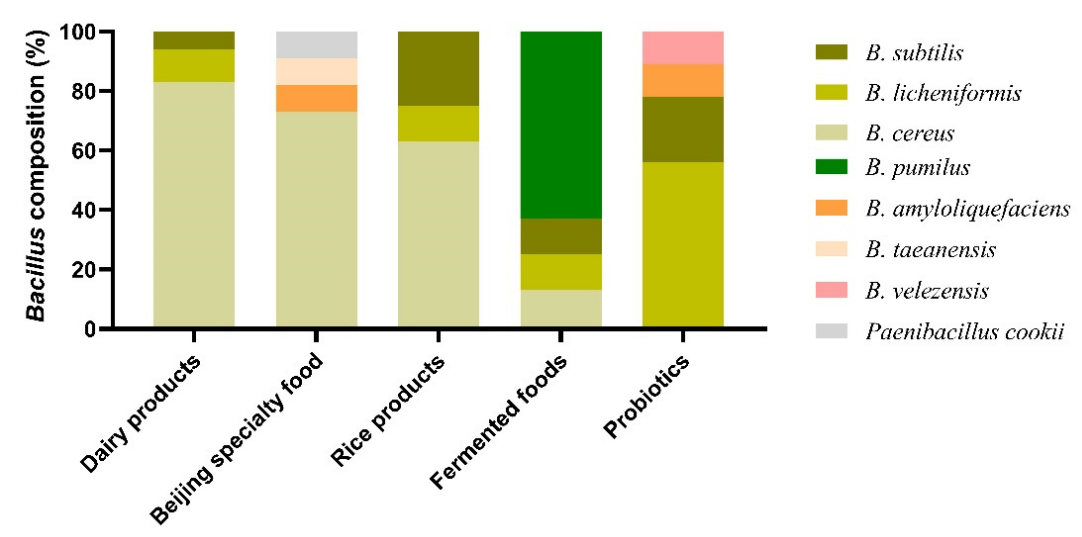

Figure 3. Compositions of Bacillus species in the samples from different sources. B. cereus is the dominant species in the isolates recovered from dairy products, Beijing specialty foods and rice products. B. pumilus and B. licheniformis are the most prevalent groups of fermented foods and probiotics-derived Bacillus strains, respectively. 


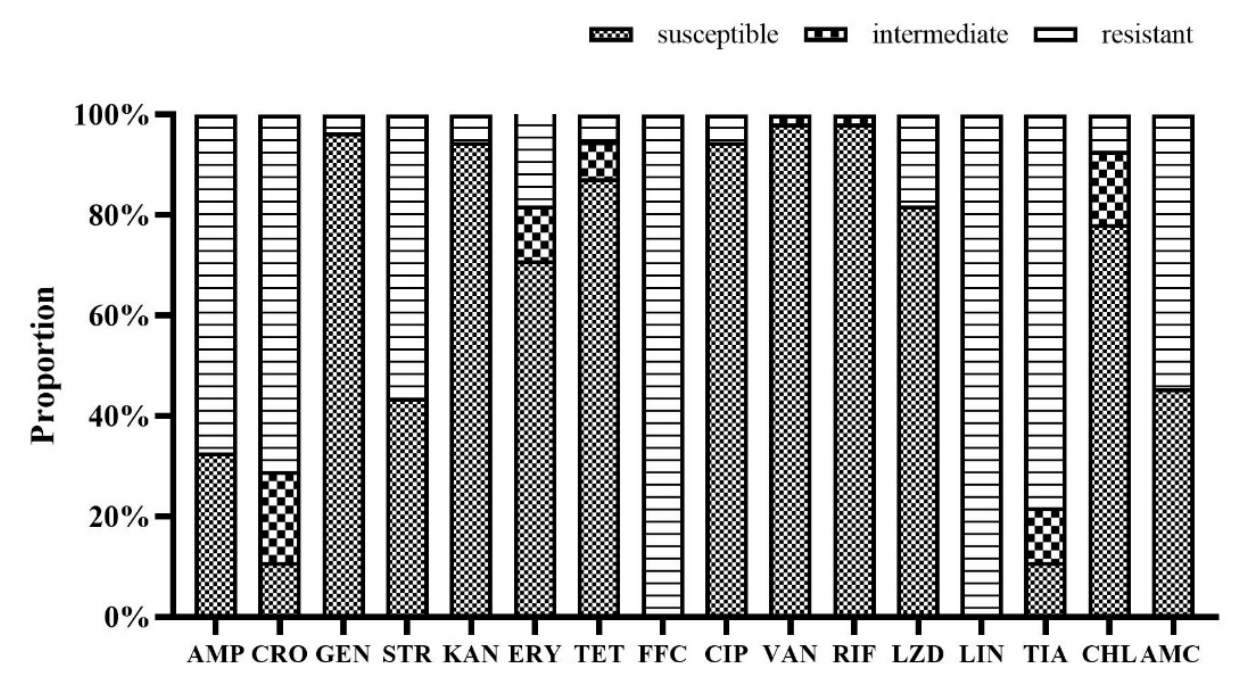

Antibiotics

Figure 4. The proportions of susceptible, intermediate and resistant strains among 55 isolated Bacillus strains to 16 antibiotics. AMC: ampicillin, CRO: ceftriaxone, GEN: gentamicin, STR: streptomycin, KAN: kanamycin, ERY: erythromycin, TET: tetracycline, FFC: florfenicol, CIP: ciprofloxacin, VAN: vancomycin, RIF: rifampicin, LZD: linezolid, LIN: lincomycin, TIA: tiamulin, CHL: chloramphenicol, AMC: amoxicillin + clavulanate.

Table 2. Proportion of Bacillus strains of different species resistant to antibiotics.

\begin{tabular}{ccccc}
\hline \multirow{2}{*}{ Antibiotics } & \multicolumn{4}{c}{ Fraction of Resistant Isolates } \\
\cline { 2 - 5 } & B. cereus & B. licheniformis & B. subtilis & B. pumilus \\
\hline AMP & $29 / 29$ & $3 / 9$ & $1 / 7$ & 0 \\
CRO & $29 / 29$ & $3 / 9$ & $1 / 7$ & $5 / 5$ \\
GEN & $2 / 29$ & 0 & 0 & 0 \\
STR & $15 / 29$ & $7 / 9$ & $7 / 7$ & 0 \\
KAN & $1 / 29$ & $1 / 9$ & 0 & 0 \\
ERY & $2 / 29$ & $7 / 9$ & 0 & 0 \\
TET & $2 / 29$ & 0 & 0 & 0 \\
FFC & $29 / 29$ & $9 / 9$ & $7 / 7$ & $5 / 5$ \\
CIP & $2 / 29$ & 0 & 0 & 0 \\
VAN & 0 & 0 & 0 & 0 \\
RIP & 0 & 0 & 0 & 0 \\
LZD & $6 / 29$ & $1 / 9$ & $3 / 7$ & 0 \\
LIN & $29 / 29$ & $9 / 9$ & $7 / 7$ & $5 / 5$ \\
TIA & $23 / 29$ & $9 / 9$ & $4 / 7$ & $4 / 5$ \\
CHL & $1 / 29$ & $2 / 9$ & 0 & 0 \\
AMC & $29 / 29$ & 0 & 0 & 0 \\
\hline
\end{tabular}

\subsection{The Antimicrobial Resistance and Virulence Genes of Bacillus Isolates}

According to the results of MIC tests, 19 Bacillus isolates were subjected to nextgeneration sequencing, and the whole genomic sequences were screened for ARGs and virulence genes. It is interpreted that $57.9 \%, 26.3 \%$ and $21.5 \%$ of Bacillus strains carried fosfomycin resistance gene $f o s B$, tetracycline resistance gene tet and erythromycin resistance gene erm, respectively (Table 3). Vancomycin resistance gene van was present in $11(100 \%)$ B. cereus isolates. In addition, 2 B. subtilis strains and 1 B. pumilus strain were found to harbor kanamycin resistance gene $a a d K$, and 1 B. pumilus isolated from fermented vegetable and $1 B$. cereus from dairy product carried chloramphenicol resistance gene cat. There was a poor consistency between the phenotypical and genetic antimicrobial resistance traits of tested strains. Interestingly, B. cereus was the only species carrying virulence genes, with 
the rates of $100 \%, 9.1 \%, 45.5 \%$ and $100 \%$ for $n h e, h b l, c y t K$ and $e n t F M$, respectively. Other virulence factor related genes include PLC, hlyIII, clo, InhA2, and so on. Therefore, Bacillus spp. derived from foods are likely to develop resistance to drugs and produce toxins that cause relevant disease.

Table 3. The antibiotic resistance genes and virulence genes of Bacillus isolates.

\begin{tabular}{|c|c|c|c|c|}
\hline Strains & Species & Sources & ARGs & VGs \\
\hline CAU475 & B. cereus & Dairy products & fos $B$, van & $\begin{array}{l}\text { clo, entFM, hlyIII, inhA2, nhe A, nheB, nheC, nprA, } \\
\text { PLC, sph }\end{array}$ \\
\hline CAU476 & B. cereus & Dairy products & fos $B$, tet $A$, van & $\begin{array}{c}\text { clo, cytK, entFM, entS, hlyIII, inhA2, nhe A, nheB, } \\
\text { nheC, nprA, PLC, sph }\end{array}$ \\
\hline CAU479 & B. cereus & Dairy products & fos $B$, van & $\begin{array}{c}\text { clo, cytK, entFM, entS, hlyIII, inhA2, nhe A, nheB, } \\
\text { nheC, nprA, PLC, sph }\end{array}$ \\
\hline CAU480 & B. cereus & Dairy products & $a a c, c a t$, fosB, van & $\begin{array}{c}\text { clo, entFM, entS, hlyIII, inhA2, nhe } A, \text { nheB, nheC, } \\
\text { nprA, PLC, sph }\end{array}$ \\
\hline CAU481 & B. cereus & Dairy products & fos $B$, van & $\begin{array}{c}\text { clo, cytK, entFM, entS, hlyIII, inhA2, nhe A, nheB, } \\
\text { nheC, nprA, PLC, sph }\end{array}$ \\
\hline CAU482 & B. cereus & Dairy products & fosB, van & $\begin{array}{c}\text { clo, entFM, entS, hlyIII, inh A2, nhe A, nheB, nheC, } \\
\text { nprA, PLC, sph }\end{array}$ \\
\hline CAU484 & B. cereus & Dairy products & fosB, van & $\begin{array}{c}\text { cesH, entFM, entS, hlyIII, inhA2, nhe A, nheB, nheC, } \\
\text { nprA, PLC, sph }\end{array}$ \\
\hline CAU486 & B. cereus & Dairy products & fos $B$, van & $\begin{array}{c}\text { cesH, entFM, entS, hlyIII, inhA2, nhe A, nheB, nheC, } \\
\text { nprA, PLC, sph }\end{array}$ \\
\hline CAU504 & B. cereus & Rice products & $f o s B$, van & $\begin{array}{l}\text { clo, entFM, entS, hblA, hblC, hblD, hlbB, hlyIII, } \\
\text { inh } A 2, \text { nhe } A, \text { nheB, nheC, nprA, PLC, sph }\end{array}$ \\
\hline CAU505 & B. cereus & Rice products & fos $B$, van & $\begin{array}{c}\text { clo, cytK, entFM, entS, hlyIII, inhA2, nhe A, nheB, } \\
\text { nheC, nprA, PLC, sph }\end{array}$ \\
\hline CAU506 & B. cereus & Rice products & fos $B$, tet $L$, van & $\begin{array}{c}\text { clo, cytK, entFM, entS, hlyIII, inhA2, nhe A, nheB, } \\
\text { nheC, nprA, PLC, sph }\end{array}$ \\
\hline CAU495 & B. licheniformis & Fermented vegetable & ermD & - \\
\hline CAU511 & B. licheniformis & Probiotics & ermD & - \\
\hline CAU514 & B. licheniformis & Probiotics & ermD & - \\
\hline CAU516 & B. licheniformis & Probiotics & ermD & - \\
\hline CAU498 & B. pumilus & Fermented vegetable & aadK, mphK, tetL & - \\
\hline CAU500 & B. pumilus & Fermented vegetable & cat & - \\
\hline CAU501 & B. subtilis & Ham & aadK, $m p h K$, tetL & - \\
\hline CAU502 & B. subtilis & Rice products & aadK, mphK, tetL & - \\
\hline
\end{tabular}

\subsection{The Hemolytic Ability and Antibacterial Effect of Bacillus Isolates}

Cytotoxicity is an important factor involved in pathogenesis of bacterium. We found that 33 out of the $55(60 \%)$ Bacillus strains caused hemolysis. Among the hemolytic isolates, $75.8 \%$ were $B$. cereus, which was recognized as a dangerous pathogen correlated with food poisoning. All 5 B. pumilus strains were hemolytic, while B. licheniformis were completely non-hemolytic. Of seven $B$. subtilis strains, two resulted in hemolysis, suggesting that a large number of Bacillus spp. have the capability of rupturing red blood cells.

We observed that 3 B. licheniformis strains (CAU495, CAU511, CAU514) exerted an inhibitory effect on the growth of S. aureus ATCC 29213, and none of the bacteria inhibited E. coli ATCC 25922 (Figure 5). B. licheniformis CAU495, CAU511 and CAU514 were obtained from fermented vegetables, pet probiotics and livestock probiotics, respectively, with diameters of the zone presented to be 2, 1.1 and $1.9 \mathrm{~cm}$. Thus, foodborne Bacillus spp. showed the potential of developing into a probiotic strain. 
a

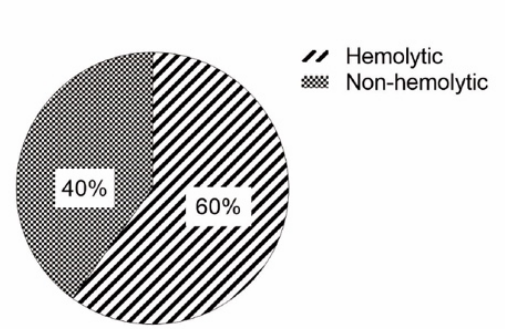

C

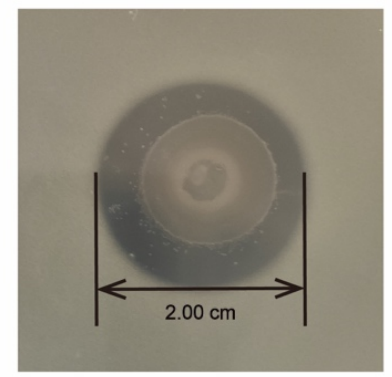

b

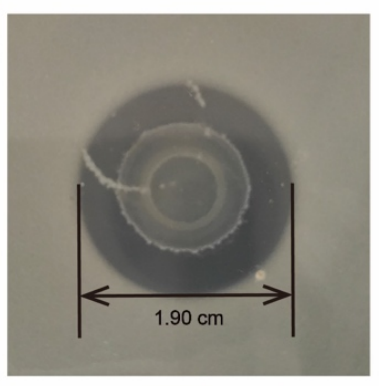

d

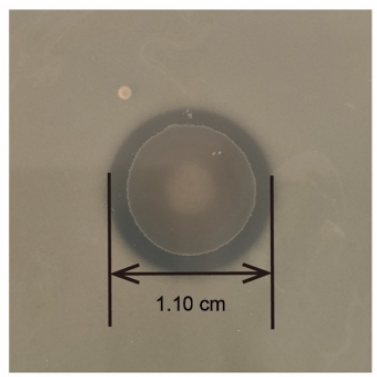

Figure 5. Results of the hemolysis test and agar overlay technique. (a) proportion of hemolytic and non-hemolytic Bacillus strains; $60 \%$ of Bacillus strains were hemolytic on sheep blood. (b-d) are the inhibition zones of B. licheniformis CAU514, CAU495 and CAU511, respectively, with S. aureus ATCC 29213 added in the soft-agar overlay.

\section{Discussion}

Our study confirmed the presence of Bacillus spp. in several kinds of foods. The highest prevalence was in dairy and rice products, illustrated by the antimicrobial resistance of 55 Bacillus isolates mainly towards florfenicol, lincomycin and florfenicol and lincomycin. Meanwhile, the virulence genes were common in B. cereus, and 3 out of 55 strains displayed the capability of attacking other organisms. In spite of the rapid advancement in the fields of food science and technology, and a growing concern raised by various international groups on food safety, prevalence of foodborne illness still remains a substantial cause of morbidity and preventable mortality [42]. Bacillus is designated as a group of soil inhabitants that also can be isolated from varied sources including vegetables and food. It represents the most heterogeneous group considering their phenotypic and genotypic characters. Some distinct species such as $B$. cereus have also been recognized as opportunistic pathogens or toxin producers in human or animal hosts. In this study, we collected 95 food samples from local markets in Beijing and 11 probiotic products purchased from other areas. A total of 55 Bacillus strains were obtained from 41 samples, mostly composed of B. cereus $(29 / 55)$. Among different categories of food products, dairy products were the most important niche, followed by specialty foods, probiotics and rice products. However, Beijing specialty foods are theoretically a sub-type of rice products, which implies that both rice products and dairy products were eligible residences for Bacillus spp. In Japan, B. cereus was found in 66 out of $101(65.3 \%)$ domestically pasteurized milk samples, which is moderately higher than the rate $(51.7 \%)$ of our study [43]. In addition, a previous study found that nearly half of the 65 isolated Bacillus spp. strains from 34 commercial probiotic products harbored multiple antimicrobial resistance genes, coupled with mobile genetic elements, and were capable of producing hazardous toxins, while no B. cereus was recovered from the 11 probiotics we collected, indicating that those samples were free from the contamination of B. cereus and its toxins [44].

We found that 55 Bacillus isolates were all resistant to florfenicol, lincomycin and had significant resistance to tiamulin, ampicillin, amoxicillin + clavulanate and ceftriaxone. 
Since $B$. cereus are able to produce $\beta$-lactamase, they are intrinsically resistant to $\beta$-lactams. It is also reported that ABC (ATP binding cassette) efflux transporters of $B$. subtilis can generate tolerance to lincosamide, which is consistent with our results [45]. Concerning the resistance genes, we disclosed that $B$. cereus, B. subtilis and B. licheniformis mainly carried fosfomycin resistance gene $f \circ s B$, tetracycline resistance gene tet and erythromycin resistance gene erm, separately. B. cereus isolates, obtained from vegetables in South Korea, were susceptible to imipenem, vancomycin, gentamicin, erythromycin, ciprofloxacin and chloramphenicol, and unlike the tendency of our results, $40.5 \%$ from romaine lettuce were resistant to rifampin and $6 \%$ of isolates from garlic chives exhibited resistance to tetracycline [46]. Moreover, 147 B. cereus sensu lato strains isolated from German market food showed resistance against the $\beta$-lactam antibiotics such as penicillin $G$ and cefotaxim $(100 \%)$, as well as amoxicillin/clavulanic acid combination and ampicillin $(99.3 \%)$, while most strains were susceptible to ciprofloxacin (99.3\%), chloramphenicol (98.6\%), imipenem $(93.9 \%)$, erythromycin $(91.8 \%)$, gentamicin $(88.4 \%)$ and tetracycline $(76.2 \%)$, which are higher than our results to a mild extent [47]. Our findings suggest that Bacillus is a group of potential foodborne pathogens harboring mobile ARGs and might undermine the therapeutic effect of antibiotics.

$B$. cereus produces a wide array of virulence factors, including pore-forming toxins, cereulide, hemolysins, enterotoxins, proteases and phospholipases [48]. We discovered here that virulence genes were undetectable in Bacillus spp., except B. cereus. The detection rates of $n h e, h b l$ and $c y t K$ were $100 \%, 9.1 \%$ and $45.5 \%$, respectively, and ces was 0 . Another study focusing on B. cereus in Chinese markets, distinguished by the sample volume (860) and sites (39 cities), revealed that $35 \%$ of ready-to-eat (RTE) food was contaminated with $B$. cereus, with $39 \%, 83 \%, 68 \%$ and $7 \%$ of the isolated strains harboring the enterotoxin-encoding gene clusters $h b l A C D$, nhe $A B C, c y t K$ and emetic toxin-encoding gene $c e s B$, respectively. The majority of the isolates were resistant to most $\beta$-lactam antibiotics and rifamycin [49], which is largely consistent with our findings. From 2013 to 2015, Kui Zhu et al. isolated 18 B. cereus group strains from 15 probiotics and discovered that all strains produced the enterotoxin Nhe, 15 strains additionally produced $\mathrm{Hbl}$, and nearly half of them harbored the antimicrobial resistance gene tet(45) [50]. In Egypt, 6.9 and 8.5\% of B. cereus were recovered from milk powder and Ras-cheese, respectively, and nhe gene was detected and dominated in all isolates (100\%) from both products [51]. A South Korean survey involving 496 samples of food from environmental and clinical origin, found that $92.3 \%$ and $59.5 \%$ of $B$. cereus strains carried nhe and $h b l$, respectively [52]. Those studies have presented that almost all $B$. cereus harbor the nhe gene, including the emetic $B$. cereus, which explains that vomiting symptoms are often accompanied with diarrhea. Regarding the hemolytic activity, most $B$. cereus could destroy blood cells, denoting their virulence towards target cells to some extent. Apart from the biological perils that have been discussed, we found encouraging evidence of 3 B. licheniformis strains that showed antimicrobial activities towards Gram-positive bacteria, indicating the potential of being probiotic candidates or antibiotic alternatives. Thus, among isolated Bacillus strains, B. cereus constitutes a principal part in generating antimicrobial resistance and virulence. Other species of Bacillus spp., on the other hand, have different phenotypical features and could even release antibacterial components.

\section{Conclusions}

Our findings connote that Bacillus spp. are distributed in a variety of food products with a potential of secreting virulent substances and disseminating antimicrobial resistance. They are also possible resources for new antibiotic substitutes. Therefore, corresponding guidelines regarding the sterilization, pasteurization and monitoring of toxins in the whole food chain, especially on-shelf foods, should be developed to further promote public health.

Supplementary Materials: The following are available online at https:/ / www.mdpi.com/article/10 .3390/pr9050866/s1, Table S1: Food sources of each Bacillus strain. 
Author Contributions: Conceptualization, Q.H. and Y.F.; methodology, Q.H.; software, Q.H.; validation, Q.H. and Y.F.; formal analysis, Q.H. and J.Z.; investigation, Q.H. and Y.F.; resources, W.X.; data curation, Q.H. and Y.F.; writing—original draft preparation, Q.H. and Y.F.; writing-review and editing, W.X. and J.Z.; visualization, J.Z.; supervision, K.Z.; project administration, K.Z.; funding acquisition, K.Z. All authors have read and agreed to the published version of the manuscript.

Funding: This research was funded by the National Key Research and Development Program of China (2017YFC1600305), Beijing Municipal Science and Technology Project (Z201100008920001) and Beijing Dairy Industry Innovation Team.

Institutional Review Board Statement: Not applicable.

Informed Consent Statement: Not applicable.

Conflicts of Interest: The authors declare no conflict of interest.

\section{References}

1. Bennett, S.D.; Sodha, S.V.; Ayers, T.L.; Lynch, M.F.; Gould, L.H.; Tauxe, R.V. Produce-associated foodborne disease outbreaks, USA, 1998-2013. Epidemiol. Infect. 2018, 146, 1397-1406. [CrossRef]

2. Schlinkmann, K.M.; Razum, O.; Werber, D. Characteristics of foodborne outbreaks in which use of analytical epidemiological studies contributed to identification of suspected vehicles, European Union, 2007 to 2011. Epidemiol. Infect. 2017, 145, 1231-1238. [CrossRef]

3. Li, W.; Pires, S.M.; Liu, Z.; Ma, X.; Liang, J.; Jiang, Y.; Chen, J.; Liang, J.; Wang, S.; Wang, L.; et al. Surveillance of foodborne disease outbreaks in China, 2003-2017. Food Control 2020, 118, 107359. [CrossRef]

4. World Health Organization. Food Safety. Available online: https://www.who.int/news-room/fact-sheets/detail/food-safety (accessed on 30 April 2020).

5. Mughini-Gras, L.; Schaapveld, M.; Kramers, J.; Mooij, S.; Neefjes-Borst, E.A.; Van Pelt, W.; Neefjes, J. Increased colon cancer risk after severe Salmonella infection. PLoS ONE 2018, 13, e0189721. [CrossRef] [PubMed]

6. Cao, Y.; Feng, T.; Xu, J.; Xue, C. Recent advances of molecularly imprinted polymer-based sensors in the detection of food safety hazard factors. Biosens. Bioelectron. 2019, 141, 111447. [CrossRef] [PubMed]

7. Fung, F.; Wang, H.-S.; Menon, S. Food safety in the 21st century. Biomed. J. 2018, 41, 88-95. [CrossRef]

8. Rajkovic, A.; Jovanovic, J.; Monteiro, S.; Decleer, M.; Andjelkovic, M.; Foubert, A.; Beloglazova, N.; Tsilla, V.; Sas, B.; Madder, A.; et al. Detection of toxins involved in foodborne diseases caused by Gram-positive bacteria. Compr. Rev. Food Sci. Food Saf. 2020, 19, 1605-1657. [CrossRef] [PubMed]

9. Bottone, E.J. Bacillus cereus, a Volatile Human Pathogen. Clin. Microbiol. Rev. 2010, 23, 382-398. [CrossRef]

10. Nicholson, W.L. Roles of Bacillus endospores in the environment. Cell. Mol. Life Sci. 2002, 59, 410-416. [CrossRef]

11. Drobniewski, F.A. Bacillus cereus and related species. Clin. Microbiol. Rev. 1993, 6, 324-338. [CrossRef]

12. Kotiranta, A.; Lounatmaa, K.; Haapasalo, M. Epidemiology and pathogenesis of Bacillus cereus infections. Microbes Infect. 2000, 2, 189-198. [CrossRef]

13. Vidic, J.; Chaix, C.; Manzano, M.; Heyndrickx, M. Food Sensing: Detection of Bacillus cereus Spores in Dairy Products. Biosensors 2020, 10, 15. [CrossRef] [PubMed]

14. Nicholson, W.L.; Munakata, N.; Horneck, G.; Melosh, H.J.; Setlow, P. Resistance of Bacillus endospores to extreme terrestrial and extraterrestrial environments. Microbiol. Mol. Biol. Rev. 2000, 64, 548-572. [CrossRef] [PubMed]

15. Bader, J.; Albin, A.; Stahl, U. Spore-forming bacteria and their utilisation as probiotics. Benef. Microbes 2012, 3, 67-75. [CrossRef] [PubMed]

16. Elshaghabee, F.M.F.; Rokana, N.; Gulhane, R.D.; Sharma, C.; Panwar, H. Bacillus as potential probiotics: Status, concerns, and future perspectives. Front. Microbiol. 2017, 8, 1490. [CrossRef] [PubMed]

17. Lefevre, M.; Racedo, S.M.; Ripert, G.; Housez, B.; Cazaubiel, M.; Maudet, C.; Jüsten, P.; Marteau, P.; Urdaci, M.C. Probiotic strain Bacillus subtilis CU1 stimulates immune system of elderly during common infectious disease period: A randomized, double-blind placebo-controlled study. Immun. Ageing 2015, 12, 1-11. [CrossRef]

18. Shobharani, P.; Padmaja, R.J.; Halami, P.M. Diversity in the antibacterial potential of probiotic cultures Bacillus licheniformis MCC2514 and Bacillus licheniformis MCC2512. Res. Microbiol. 2015, 166, 546-554. [CrossRef] [PubMed]

19. Ripert, G.; Racedo, S.M.; Elie, A.-M.; Jacquot, C.; Bressollier, P.; Urdaci, M.C. Secreted Compounds of the Probiotic Bacillus clausii strain $\mathrm{O} / \mathrm{C}$ inhibit the cytotoxic effects induced by Clostridium difficile and Bacillus cereus toxins. Antimicrob. Agents Chemother. 2016, 60, 3445-3454. [CrossRef]

20. Terlabie, N.N.; Sakyi-Dawson, E.; Amoa-Awua, W.K. The comparative ability of four isolates of Bacillus subtilis to ferment soybeans into dawadawa. Int. J. Food Microbiol. 2006, 106, 145-152. [CrossRef]

21. Cochrane, S.A.; Vederas, J.C. Lipopeptides from Bacillus and Paenibacillus spp.: A gold mine of antibiotic candidates. Med. Res. Rev. 2016, 36, 4-31. [CrossRef]

22. Zhao, H.; Shao, D.; Jiang, C.; Shi, J.; Li, Q.; Huang, Q.; Rajoka, M.S.R.; Yang, H.; Jin, M. Biological activity of lipopeptides from Bacillus. Appl. Microbiol. Biotechnol. 2017, 101, 5951-5960. [CrossRef] [PubMed] 
23. Bareia, T.; Pollak, S.; Eldar, A. Self-sensing in Bacillus subtilis quorum-sensing systems. Nat. Microbiol. 2018, 3, 83-89. [CrossRef] [PubMed]

24. Jennings-Antipov, L.D.; Song, L.; Collier, R.J. Interactions of anthrax lethal factor with protective antigen defined by site-directed spin labeling. Proc. Natl. Acad. Sci. USA 2011, 108, 1868-1873. [CrossRef] [PubMed]

25. Toh, M.; Moffitt, M.C.; Henrichsen, L.; Raftery, M.; Barrow, K.; Cox, J.M.; Marquis, C.P.; Neilan, B.A. Cereulide, the emetic toxin of Bacillus cereus, is putatively a product of nonribosomal peptide synthesis. J. Appl. Microbiol. 2004, 97, 992-1000. [CrossRef] [PubMed]

26. Andersson, M.A.; Hakulinen, P.; Honkalampi-Hämäläinen, U.; Hoornstra, D.; Lhuguenot, J.-C.; Mäki-Paakkanen, J.; Savolainen, M.; Severin, I.; Stammati, A.-L.; Turco, L.; et al. Toxicological profile of cereulide, the Bacillus cereus emetic toxin, in functional assays with human, animal and bacterial cells. Toxicon 2007, 49, 351-367. [CrossRef] [PubMed]

27. Rouzeau-Szynalski, K.; Stollewerk, K.; Messelhäusser, U.; Ehling-Schulz, M. Why be serious about emetic Bacillus cereus: Cereulide production and industrial challenges. Food Microbiol. 2020, 85, 103279. [CrossRef] [PubMed]

28. Tran, S.-L.; Guillemet, E.; Ngo-Camus, M.; Clybouw, C.; Puhar, A.; Moris, A.; Gohar, M.; Lereclus, D.; Ramarao, N. Haemolysin II is a Bacillus cereus virulence factor that induces apoptosis of macrophages. Cell. Microbiol. 2010, 13, 92-108. [CrossRef] [PubMed]

29. Jeßberger, N.; Dietrich, R.; Bock, S.; Didier, A.; Märtlbauer, E. Bacillus cereus enterotoxins act as major virulence factors and exhibit distinct cytotoxicity to different human cell lines. Toxicon 2014, 77, 49-57. [CrossRef]

30. Dietrich, R.; Jessberger, N.; Ehling-Schulz, M.; Märtlbauer, E.; Granum, P.E. The food poisoning toxins of Bacillus cereus. Toxins 2021, 13, 98. [CrossRef]

31. Berendonk, T.U.; Manaia, C.M.; Merlin, C.; Fatta-Kassinos, D.; Cytryn, E.; Walsh, F.; Buergmann, H.; Sørum, H.; Norström, M.; Pons, M.-N.; et al. Tackling antibiotic resistance: The environmental framework. Nat. Rev. Microbiol. 2015, 13, 310-317. [CrossRef] [PubMed]

32. Cabello, F.C.; Godfrey, H.P.; Buschmann, A.H.; Dölz, H.J. Aquaculture as yet another environmental gateway to the development and globalisation of antimicrobial resistance. Lancet Infect. Dis. 2016, 16, e127-e133. [CrossRef]

33. Friedman, N.; Temkin, E.; Carmeli, Y. The negative impact of antibiotic resistance. Clin. Microbiol. Infect. 2016, $22,416-422$. [CrossRef]

34. Nolte, O. Antimicrobial resistance in the 21st century: A multifaceted challenge. Protein Pept. Lett. 2014, 21, 330-335. [CrossRef] [PubMed]

35. Glasset, B.; Herbin, S.; Guillier, L.; Cadel-Six, S.; Vignaud, M.-L.; Grout, J.; Pairaud, S.; Michel, V.; Hennekinne, J.-A.; RamaRao, N.; et al. Bacillus cereus-induced food-borne outbreaks in France, 2007 to 2014: Epidemiology and genetic characterisation. Eurosurveillance 2016, 21. [CrossRef] [PubMed]

36. European Food Safety Authority; European Centre for Disease Prevention and Control. The European Union summary report on trends and sources of zoonoses, zoonotic agents and food-borne outbreaks in 2016. EFSA J. 2017, 15, e05077. [CrossRef]

37. Anderson Borge, G.I.; Skeie, M.; Sørhaug, T.; Langsrud, T.; Granum, P.E. Growth and toxin profiles of Bacillus cereus isolated from different food sources. Int. J. Food Microbiol. 2001, 69, 237-246. [CrossRef]

38. Liu, X.-Y.; Hu, Q.; Xu, F.; Ding, S.-Y.; Zhu, K. Characterization of Bacillus cereus in dairy products in China. Toxins 2020, $12,454$. [CrossRef]

39. Jessberger, N.; Dietrich, R.; Granum, P.E.; Märtlbauer, E. The Bacillus cereus food infection as multifactorial process. Toxins 2020, 12, 701. [CrossRef] [PubMed]

40. Bennett, S.D.; Walsh, K.A.; Gould, L.H. Foodborne disease outbreaks caused by Bacillus cereus, Clostridium perfringens, and Staphylococcus aureus-United States, 1998-2008. Clin. Infect. Dis. 2013, 57, 425-433. [CrossRef] [PubMed]

41. Lane, D.J. 16S/23S rRNA Sequencing. Nucleic Acid Techniques in Bacterial Systematic; Wiley: Chichester, UK; New York, NY, USA, 1991; pp. 115-175.

42. Akhtar, S.; Sarker, M.R.; Hossain, A. Microbiological food safety: A dilemma of developing societies. Crit. Rev. Microbiol. 2012, 40, 348-359. [CrossRef]

43. Shimojima, Y.; Kodo, Y.; Soeda, K.; Koike, H.; Kanda, M.; Hayashi, H.; Nishino, Y.; Fukui, R.; Kuroda, S.; Hirai, A.; et al. Prevalence of Cereulide-producing Bacillus cereus in pasteurized milk. Shokuhin Eiseigaku Zasshi 2020, 61, 178-182. [CrossRef] [PubMed]

44. Cui, Y.; Wang, S.; Ding, S.; Shen, J.; Zhu, K. Toxins and mobile antimicrobial resistance genes in Bacillus probiotics constitute a potential risk for One Health. J. Hazard. Mater. 2020, 382, 121266. [CrossRef] [PubMed]

45. Ohki, R.; Tateno, K.; Takizawa, T.; Aiso, T.; Murata, M. Transcriptional termination control of a novel ABC transporter gene involved in antibiotic resistance in Bacillus subtilis. J. Bacteriol. 2005, 187, 5946-5954. [CrossRef]

46. Park, K.M.; Jeong, M.; Park, K.J.; Koo, M. Prevalence, enterotoxin genes, and antibiotic resistance of Bacillus cereus Isolated from raw vegetables in Korea. J. Food Prot. 2018, 81, 1590-1597. [CrossRef]

47. Fiedler, G.; Schneider, C.; Igbinosa, E.O.; Kabisch, J.; Brinks, E.; Becker, B.; Stoll, D.A.; Cho, G.-S.; Huch, M.; Franz, C.M.A.P. Antibiotics resistance and toxin profiles of Bacillus cereus-group isolates from fresh vegetables from German retail markets. BMC Microbiol. 2019, 19, 250. [CrossRef] [PubMed]

48. Enosi Tuipulotu, D.; Mathur, A.; Ngo, C.; Man, S.M. Bacillus cereus: Epidemiology, virulence factors, and host-pathogen interactions. Trends Microbiol. 2021, 29, 458-471. [CrossRef]

49. Yu, S.; Yu, P.; Wang, J.; Li, C.; Guo, H.; Liu, C.; Kong, L.; Yu, L.; Wu, S.; Lei, T.; et al. A Study on prevalence and characterization of Bacillus cereus in Ready-to-Eat foods in China. Front. Microbiol. 2020, 10, 3043. [CrossRef] [PubMed] 
50. Zhu, K.; Hölzel, C.S.; Cui, Y.; Mayer, R.; Wang, Y.; Dietrich, R.; Didier, A.; Bassitta, R.; Märtlbauer, E.; Ding, S. Probiotic Bacillus cereus strains, a potential risk for public health in China. Front. Microbiol. 2016, 7, 718. [CrossRef]

51. Abdeen, E.E.-S.; Hussien, H.; Hadad, G.A.E.; Mousa, W.S. Prevalence of virulence determinants among Bacillus cereus isolated from milk products with potential public health concern. Pak. J. Biol. Sci. 2020, 23, 206-212. [CrossRef] [PubMed]

52. Forghani, F.; Kim, J.-B.; Oh, D.-H. Enterotoxigenic profiling of emetic toxin- and enterotoxin-producing Bacillus cereus, isolated from food, environmental, and clinical samples by multiplex PCR. J. Food Sci. 2014, 79, M2288-M2293. [CrossRef] 